\title{
Tungsten-Based Metallic Glasses with High Crystallization Temperature, High Modulus and High Hardness
}

\author{
Madoka Ohtsuki*1, Kyoko Nagata*2, Ryuji Tamura and Shin Takeuchi \\ Department of Materials Science and Technology, Tokyo University of Science, Noda 278-8510, Japan
}

Ternary and quaternary tungsten-based alloys were melt-spun to produce metallic glasses having high crystallization temperature and high hardness. Alloy compositions were selected based on eutectic compositions of tungsten-based binary alloys; they are $\mathrm{W}_{46} \mathrm{Ru}_{37} \mathrm{~B}_{17}, \mathrm{~W}_{54} \mathrm{Rh}_{26} \mathrm{~B}_{20}$, $\mathrm{W}_{56} \mathrm{Ir}_{23} \mathrm{~B}_{21}$, etc. In most of the alloys, ductile metallic glasses were produced. DSC measurements showed that most of the metallic glasses undergo a two-step crystallization with the onset temperature of the first crystallization being as high as $1049 \sim 1298 \mathrm{~K}$. Vickers hardness values at room temperature are $13 \sim 17 \mathrm{GPa}$. The ratio of the hardness $H_{\mathrm{v}}$ to Young's modulus $E$ satisfies the general rule for metallic glasses, i.e. $H_{\mathrm{V}} / E \fallingdotseq 0.06$. High temperature hardness measurements for $\mathrm{W}_{46} \mathrm{Ru}_{37} \mathrm{~B}_{17}$ and $\mathrm{W}_{45} \mathrm{Re}_{23} \mathrm{Ru}_{15} \mathrm{~B}_{17}$ metallic glasses showed that the Vickers hardness values are higher than $10 \mathrm{GPa}$ up to $900 \mathrm{~K}$.

(Received September 17, 2004; Accepted November 24, 2004)

Keywords: melt-spinning, tungsten alloys, metallic glasses, crystallization temperature, hardness

\section{Introduction}

Metallic glasses, i.e. amorphous alloys produced during solidification from the melt, possess various excellent properties, compared with their crystallized state, such as high strength and toughness, high corrosion resistance and good soft magnetic properties for ferromagnetic alloys. Until 1980's, however, most metallic glasses have been produced only as thin foil samples, which restricts the usefulness for application of the excellent properties of the metallic glasses, particularly of their high strength. Since the end of 1980's, Inoue et al. have succeeded in producing bulk metallic glasses with a thickness of several millimeters to a few centimeters for various multi-component alloys. ${ }^{1)}$ The synthesis of bulk metallic glasses has expanded the application fields of metallic glasses. ${ }^{2)}$

An inherent drawback of metallic glasses is that they cannot be used at high temperatures, because any metallic glass is in a non-equilibrium metastable state and must undergo phase transformation to a crystalline sate at a high temperature. The crystallization temperature is generally higher for alloys of higher melting point. Thus, metallic glasses which are based on refractory metals with high melting point are expected to have a high crystallization temperature and hence would be utilized up to a rather high temperature. Refractory metals with high cohesive energies have generally high elastic modulus and high hardness; it is established that Young's modulus $E$ and the Vickers hardness value $H_{\mathrm{V}}$ are correlated by $H_{\mathrm{V}} \fallingdotseq 0.06 E^{3,4)}$ Thus, metallic glasses based on refractory metals can have three advantages over those based on non-refractory metals, i.e. high crystallization temperature, high modulus and high hardness.

In the present study, an attempt to produce metallic glasses based on tungsten having the highest melting point among elements was made. Some of the results on a ternary alloy have been recently reported by the present authors. ${ }^{5)}$

\footnotetext{
${ }^{* 1}$ Graduate Student, Tokyo University of Science. Present address: Japan Manned Space System Corporation, Tsuchiura 300-0033, Japan

${ }^{* 2}$ Undergraduate Student, Tokyo University of Science
}

\section{Experimental Procedures}

\subsection{Alloy selection}

An investigation has been performed to produce tungstenbased metallic glasses with glass forming ability as high as possible aiming at fabricating a bulk metallic glass of thickness of the order of $\mathrm{mm}$. Accordingly, ternary and quaternary tungsten based alloys were prepared in this work.

It is well established that an alloy composition yielding a deep eutectoid with a reduced melting point has generally a high glass forming ability; it has long been established that the larger is the reduced glass transition temperature defined by $t_{\mathrm{g}}=T_{\mathrm{g}} / T_{\mathrm{m}}$ ( $T_{\mathrm{g}}$ : glass transition temperature; $T_{\mathrm{m}}$ : melting point), the higher is the glass forming ability. ${ }^{6)}$ Among tungsten-based binary alloys, eutectoid forms in a tungsten rich side for $\mathrm{W}-\mathrm{Ru}\left(T_{\mathrm{e}}=2523 \mathrm{~K}\right.$ at $\left.45 \mathrm{at} \%\right)$, W-B $\left(T_{\mathrm{e}}=\right.$ $2873 \mathrm{~K}$ at $27 \mathrm{at} \%) \mathrm{W}-\mathrm{Os}\left(T_{\mathrm{e}}=2998 \mathrm{~K}\right.$ at $\left.41 \mathrm{at} \%\right), \mathrm{W}-\mathrm{Rh}$ $\left(T_{\mathrm{e}}=2513 \mathrm{~K}\right.$ at $\left.23 \mathrm{at} \%\right), \mathrm{W}-\mathrm{Zr}\left(T_{\mathrm{e}}=2737 \mathrm{~K}\right.$ at $\left.30 \mathrm{at} \%\right)$ and $\mathrm{W}-\operatorname{Re}\left(T_{\mathrm{e}}=2998 \mathrm{~K}\right.$ at $\left.41 \mathrm{at} \%\right)$, where $T_{\mathrm{e}}$ is the eutectic temperature.

Since there are few informations of phase diagrams of tungsten based multi-component alloys, alloy compositions of multi-component alloys which would have a low melting point by referring to eutectic compositions of binary systems were selected in the following way. The concentration of each alloy component $\mathrm{A}, \mathrm{B}, \cdots$ in a multi-component $\mathrm{W}$-A$\mathrm{B} \cdots$ alloy has been determined so that the composition ratios of $c^{\mathrm{W}}: c^{\mathrm{A}}, c^{\mathrm{W}}: c^{\mathrm{B}}, \cdots$ are equal to $c_{\mathrm{e}}{ }^{\mathrm{W}}: c_{\mathrm{e}}{ }^{\mathrm{A}}, c_{\mathrm{e}}{ }^{\mathrm{W}}: c_{\mathrm{e}}{ }^{\mathrm{B}}, \cdots$, respectively, where the superscript indicates the element and the subscript e signifies eutectoid. According to this principle, $\mathrm{W}_{46} \mathrm{Ru}_{37} \mathrm{~B}_{17}, \mathrm{~W}_{44} \mathrm{Os}_{40} \mathrm{~B}_{16}, \mathrm{~W}_{54} \mathrm{Rh}_{26} \mathrm{~B}_{20}$ and $\mathrm{W}_{56} \mathrm{Ir}_{23} \mathrm{~B}_{21}$ alloys were selected as ternary system and $\mathrm{W}_{45} \mathrm{Re}_{23} \mathrm{Ru}_{15} \mathrm{~B}_{17}, \mathrm{~W}_{37} \mathrm{Rh}_{18} \mathrm{Ru}_{31} \mathrm{~B}_{14}$ and $\mathrm{W}_{38} \mathrm{Ir}_{17} \mathrm{Ru}_{31} \mathrm{~B}_{14}$ alloys were selected as quaternary system Among the alloys, for the ternary metallic glass of $\mathrm{W}_{46} \mathrm{Ru}_{37} \mathrm{~B}_{17}$ alloy which has a rather high glass forming ability, a further improvement of the glass forming ability was attempted by adding further elements. As noted by Inoue, ${ }^{1)}$ it is known that use of elements having mutually different atomic radii by more than $12 \%$ enhances the glass forming ability. Hence, a smaller 
element $\mathrm{Si}$ and a larger element Hf were added in an attempt to enhance the glass forming ability. The ratios of the Glodschmidt atomic radii of $\mathrm{B}, \mathrm{Si}, \mathrm{Ru}$ and $\mathrm{Hf}$ to that of $\mathrm{W}$ are $0.66,0.85,0.97$ and 1.17, respectively. Quaternary alloys of $\mathrm{W}_{46} \mathrm{Ru}_{37} \mathrm{~B}_{17-x} \mathrm{Si}_{x},(x=2,5,10)$ and $\mathrm{W}_{45} \mathrm{Ru}_{36} \mathrm{~B}_{17 \mathrm{~F}} \mathrm{Hf}_{2}$ were selected to be produced.

\subsection{Specimen preparation}

For producing mother alloys, high purity materials with purity better than $99.9 \%$ were used, except for B having $99.5 \%$ purity. All the mother alloys were produced by arcmelting the designated amounts of the high purity materials in an argon atmosphere. Each mother alloy was melt-spun with a single-roller melt-spinning apparatus by high frequency induction heating under an argon pressure of $10^{-2} \mathrm{~Pa}$. Although the melting point of the alloys was above $1773 \mathrm{~K}$, a quartz nozzle was successfully employed to melt-spin the alloys. Splat-quenching was made onto a copper roller with a diameter of $250 \mathrm{~mm}$ rotating at around $5000 \mathrm{rpm}$.

\subsection{Structure evaluation}

The crystal structure of the melt-spun samples was examined by X-ray diffractometry with $\mathrm{CuK} \alpha$ radiation. For some samples, the structure change upon annealing was investigated with a high temperature X-ray diffractometer, K-ALPHAI(RIGAKU); samples were glued on a platinum holder with ceramic paste. For samples which showed halo pattern in the X-ray diffraction spectrum (XDS), differential scanning calorimetry (DSC) measurement was performed to determine the glass transition temperature and the crystallization temperature; the measurements were made under an argon atmosphere from the room temperature up to $1773 \mathrm{~K}$ at a heating rate of $0.33 \mathrm{~K} / \mathrm{s}$. Some samples were chemically analyzed with an electron probe microanalyzer (EPMA:JXA8900).

\subsection{Mechanical measurements}

Ductility of samples was evaluated by bending to $180^{\circ}$ and each sample was assigned as ductile if it did not break and as brittle if it broke.

For amorphous and ductile samples, Young's modulus was measured with a tensile test. In this method, Young's modulus was evaluated from the change of the distance of the two markers directly put on a ribbon sample which was measured accurately with an optical extensometer during tensile testing.

Micro-Vickers hardness measurements were performed by applying loads of 10, 20, 30, 50 and $100 \mathrm{gf}$ at a rate of $2 \mathrm{gf} / \mathrm{s}$ on a mirror face of ribbon samples which were glued on a silicon wafer. The sizes of indentation marks were measured with a scanning electron microscope. High temperature Vickers hardness measurements were also performed for some samples with a high temperature hardness testing machine (NIKON) up to $1173 \mathrm{~K}$ by applying a load of 50,100 or $200 \mathrm{gf}$ for $30 \mathrm{~s}$ at a temperature interval of $50 \mathrm{~K}$ or $100 \mathrm{~K}$.

\section{Results}

\subsection{Formation of metallic glasses and their stability}

In every alloy, the melt-span samples have a ribbon shape

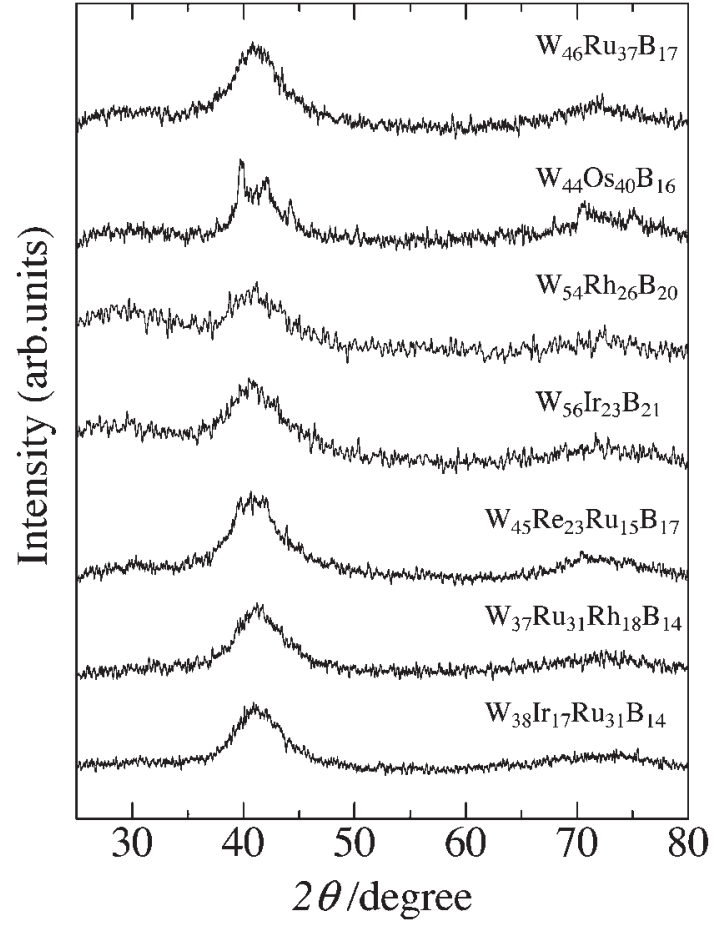

Fig. 1 X-ray diffraction spectra for as-quenched samples of four ternary and three quaternary W-based alloys. The composition of each alloy is indicated in the figure.

with a thickness of about $30 \mu \mathrm{m}$ and a width of about $1 \mathrm{~mm}$. Figure 1 shows X-ray diffraction spectra for melt-spun samples of ternary and quaternary tungsten-based alloys. The diffraction spectra show only broad halo peaks at around $2 \theta=40^{\circ}$ and $70^{\circ}$ except $\mathrm{W}_{44} \mathrm{Os}_{40} \mathrm{~B}_{16}$ and $\mathrm{W}_{45} \mathrm{Re}_{23} \mathrm{Ru}_{15} \mathrm{~B}_{17}$ alloys; in the former clear crystalline peaks overlap the halo peaks and in the latter some irregularity is seen in the main halo peak but might be due to noise in the measurement. In every sample an amorphous phase is produced at least partly. In order to evaluate the quality of the produced metallic glasses, $180^{\circ}$ bending test was performed and the results are tabulated in Table 1. Assuming that brittleness is due to the presence of some crystalline phase which was not detected in $\mathrm{X}$-ray diffraction spectrum, $\mathrm{W}_{56} \mathrm{Ir}_{23} \mathrm{~B}_{21}$ alloy may contain some crystalline phase; thus, it was concluded that except $\mathrm{W}$ Os-B and W-Ir-B ternary alloys, high quality amorphous

Table 1 Results of X-ray diffraction spectrum, $180^{\circ}$-bending test, and crystallization temperature $T_{\mathrm{x}}$ for melt-spun tungsten based alloys.

\begin{tabular}{llcc}
\hline \multicolumn{1}{c}{ Alloy $(\mathrm{K})$} & \multicolumn{1}{c}{ XDS } & $180^{\circ}$ bending & $T_{\mathrm{X} 1}(\mathrm{~K}), T_{\mathrm{X} 2}$ \\
\hline $\mathrm{W}_{46} \mathrm{Ru}_{37} \mathrm{~B}_{17}$ & halo & ductile & 1174,1208 \\
$\mathrm{~W}_{44} \mathrm{Oss}_{40} \mathrm{~B}_{16}$ & halo+peaks & brittle & 1298,1327 \\
$\mathrm{~W}_{54} \mathrm{Rh}_{26} \mathrm{~B}_{20}$ & halo & ductile & 1064,1152 \\
$\mathrm{~W}_{56} \mathrm{Ir}_{23} \mathrm{~B}_{21}$ & halo & brittle & 1271,1305 \\
$\mathrm{~W}_{45} \mathrm{Re}_{23} \mathrm{Ru}_{15} \mathrm{~B}_{17}$ & halo & ductile & $1273-$ \\
$\mathrm{W}_{37} \mathrm{Ru}_{31} \mathrm{Rh}_{18} \mathrm{~B}_{14}$ & halo & ductile & $1049-$ \\
$\mathrm{W}_{38} \mathrm{Ir}_{17} \mathrm{Ru}_{31} \mathrm{~B}_{14}$ & halo & ductile & 1119,1232 \\
$\mathrm{~W}_{46} \mathrm{Ru}_{37} \mathrm{~B}_{15} \mathrm{Si}_{2}$ & halo & ductile & 1167,1201 \\
$\mathrm{~W}_{46} \mathrm{Ru}_{37} \mathrm{~B}_{12} \mathrm{Si}_{5}$ & halo & ductile & 1172,1202 \\
$\mathrm{~W}_{46} \mathrm{Ru}_{37} \mathrm{~B}_{7} \mathrm{Si}_{10}$ & halo+peaks & brittle & 1173,1212 \\
$\mathrm{~W}_{45} \mathrm{Ru}_{36} \mathrm{~B}_{17} \mathrm{Hf}_{2}$ & halo+peaks & ductile & 1180,1222 \\
\hline
\end{tabular}




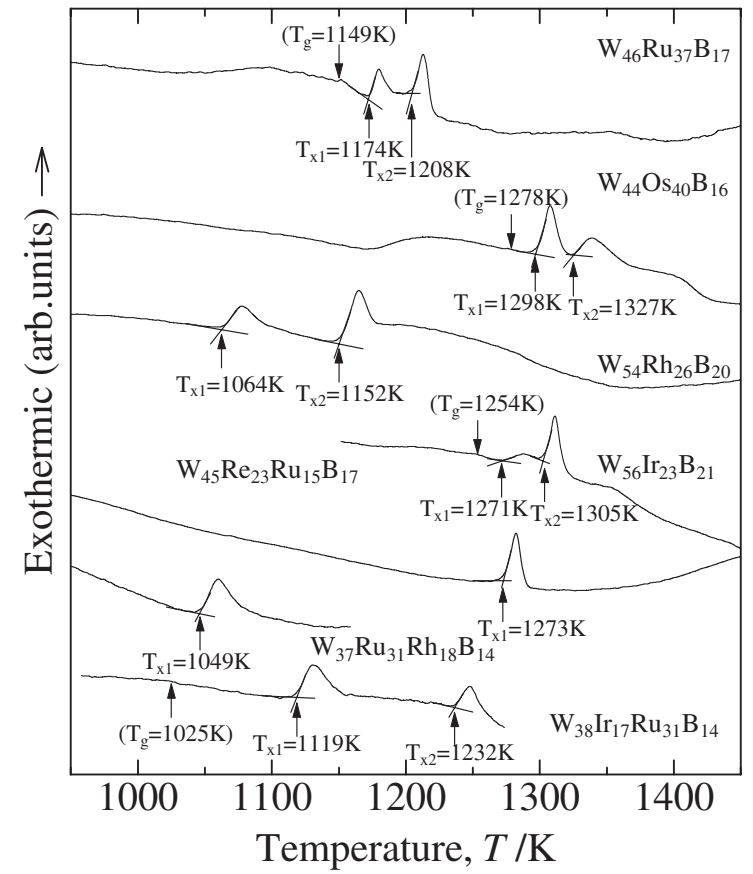

Fig. 2 DSC curves for seven as-quenched samples corresponding to those in Fig. 1. Heating rate was $0.33 \mathrm{~K} / \mathrm{s}$. Onset temperature of the first crystallization $T_{\mathrm{x} 1}$ and that of the second crystallization $T_{\mathrm{x} 2}$ are indicated on each curve. Tentatively determined glass transition temperature is given in parentheses for some alloys.

sample was produced.

Figure 2 shows DSC curves around crystallization temperatures obtained for as-spun samples shown in Fig. 1. We see clear exothermic peak or peaks corresponding to crystallization process; two peaks indicate that crystallization takes place in two-steps. We defined the crystallization temperatures at the onset of the peaks and are tabulated in Table 1. We see that the crystallization temperatures are quite high as expected. The glass transition temperature $T_{\mathrm{g}}$ is generally defined in the DSC curve by the temperature below the crystallization temperature at which the slope of the exothermic DSC curve changes downwards. However, the glass transition temperature cannot be well defined in Fig. 2, and only tentatively determined $T_{\mathrm{g}}$ values for some alloys are parenthesized in the figure. In every sample, the melting point at which an endothermic peak should appear was higher than $1773 \mathrm{~K}$ (the maximum temperature reached by the DSC measurement) and could not be determined, and hence the reduced glass transition temperature is not known.

The results of X-ray diffraction spectra and DSC curves for W-Ru-B-Si and W-Ru-B-Hf quaternary alloys are presented in Fig. 3 and Fig. 4, respectively. The results of the XDS and DSC measurements for these alloys are also tabulated in Table 1. Crystallization temperatures are not much changed compared with the ternary $\mathrm{W}_{46} \mathrm{Ru}_{37} \mathrm{~B}_{17}$ alloy. Since the glass transition temperature was not well recognized, it is difficult to judge whether or not the glass forming ability is increased by $\mathrm{Si}$ or Hf addition.

EPMA analysis of the melt-spun ribbon samples of W-Ru$\mathrm{B}-\mathrm{Hf}$ alloys indicated that the compositions of both $\mathrm{W}$ and $\mathrm{Ru}$ were less than the nominal compositions by $0 \sim 5$ at $\%$ and instead the composition of $\mathrm{B}$ was larger than the nominal
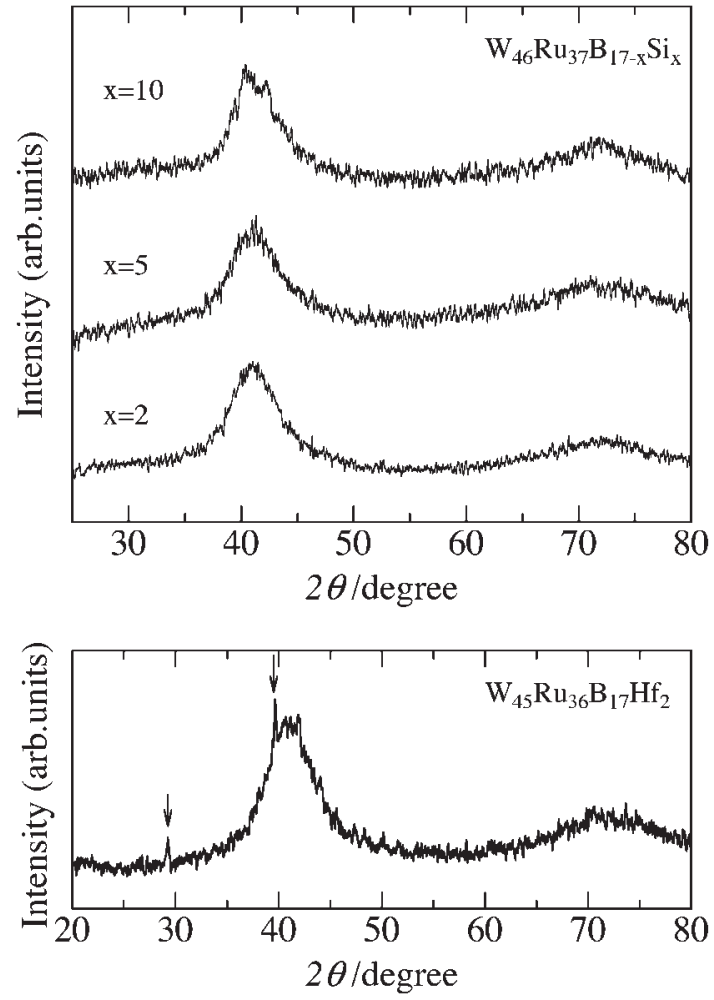

Fig. 3 X-ray diffraction spectra of as-quenched samples of three (W-RuB)-Si alloys and a W-Ru-B-Hf alloy. Sharp peaks indicated by arrows are due to Hf rich crystalline particle.
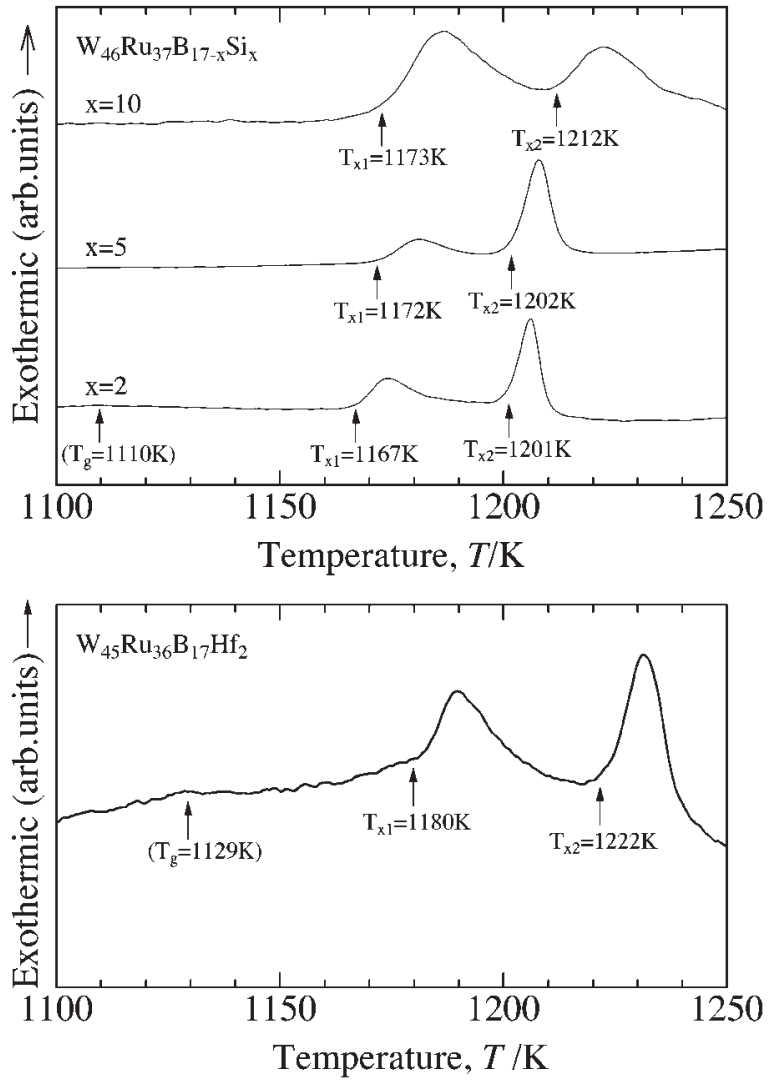

Fig. 4 DSC curves for four as-quenched samples corresponding to those in Fig. 3. 
composition by several at $\%$. However, considering a rather large scatter of the data, only the nominal compositions are shown in this paper. The observed decrease of the average concentrations by a few at $\%$ of $\mathrm{W}$ and $\mathrm{Ru}$ might be due to evaporation as oxides of $\mathrm{W}$ and $\mathrm{Ru}$ by oxidation during meltspinning process. Contamination by $\mathrm{Si}$ from quartz nozzle during melt-spinning process was found to be about 0.5 at $\%$. In the melt-spun sample of $\mathrm{W}_{45} \mathrm{Ru}_{36} \mathrm{~B}_{17} \mathrm{Hf}_{2}$, it was found that $\mathrm{Hf}$ rich crystalline particles of a diameter of a few tens $\mu \mathrm{m}$ are dispersed in the matrix and the sharp diffraction peaks indicated by arrows in Fig. 3 are from the Hf rich crystalline phase.

The changes of X-ray diffraction spectrum after heating the samples of melt-spun $\mathrm{W}_{46} \mathrm{Ru}_{37} \mathrm{~B}_{17}$ alloy up to three different temperatures, $873 \mathrm{~K}$ (well below $T_{\mathrm{x} 1}$ ), $1198 \mathrm{~K}$ (between $T_{\mathrm{x} 1}$ and $T_{\mathrm{x} 2}$ ) and $1773 \mathrm{~K}$ (well above crystallization peaks), at a rate of $0.33 \mathrm{~K} / \mathrm{s}$ are shown in Fig. 5. As expected from the DSC measurement no crystalline peak appears at $873 \mathrm{~K}$. After the first step crystallization temperature, the produced crystalline phases are $\mathrm{WB}, \mathrm{WRuB}_{2}$ and an unknown phase. After heated up to $1773 \mathrm{~K}$, the alloy will be in the thermal equilibrium consisting of three phases, bcc $\mathrm{W}-\mathrm{Ru}, \mathrm{W}_{2} \mathrm{~B}$ and another unknown phase.

In the in-situ X-ray measurement during annealing the asquenched W-Ru-B alloy, no change was recognized in the shape of the main halo peak below $923 \mathrm{~K}$. However, as shown in Fig. 6, at $998 \mathrm{~K}$ a slight change of the halo peak is observed and at $1073 \mathrm{~K}$ some irregularities in the halo peak clearly appear, indicating structural change of the amorphous structure possibly due to partial crystallization. At $1123 \mathrm{~K}$ obvious splitting of the halo peak occurs. This result indicates that local crystallization begins by about $100 \mathrm{~K}$ below the

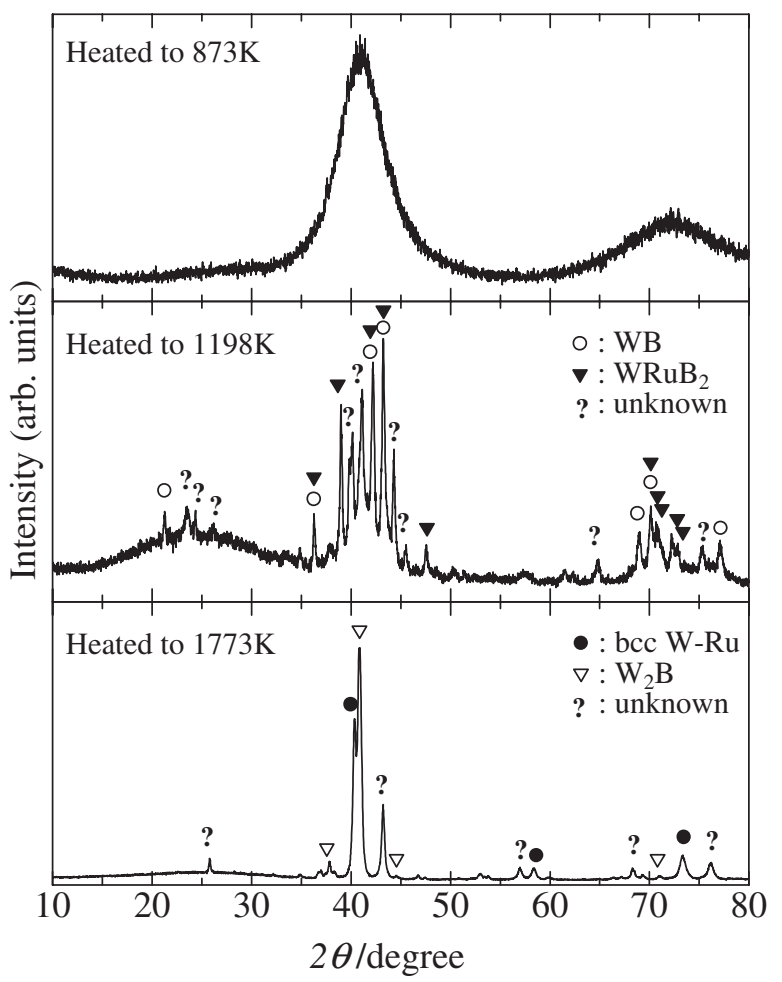

Fig. 5 X-ray diffraction spectra for $\mathrm{W}_{46} \mathrm{Ru}_{37} \mathrm{~B}_{17}$ sample after heated to $873 \mathrm{~K}$ (a), to $1198 \mathrm{~K}$ (between $T_{\mathrm{x} 1}$ and $T_{\mathrm{x} 2}$ ) (b) and to $1773 \mathrm{~K}$ (c).

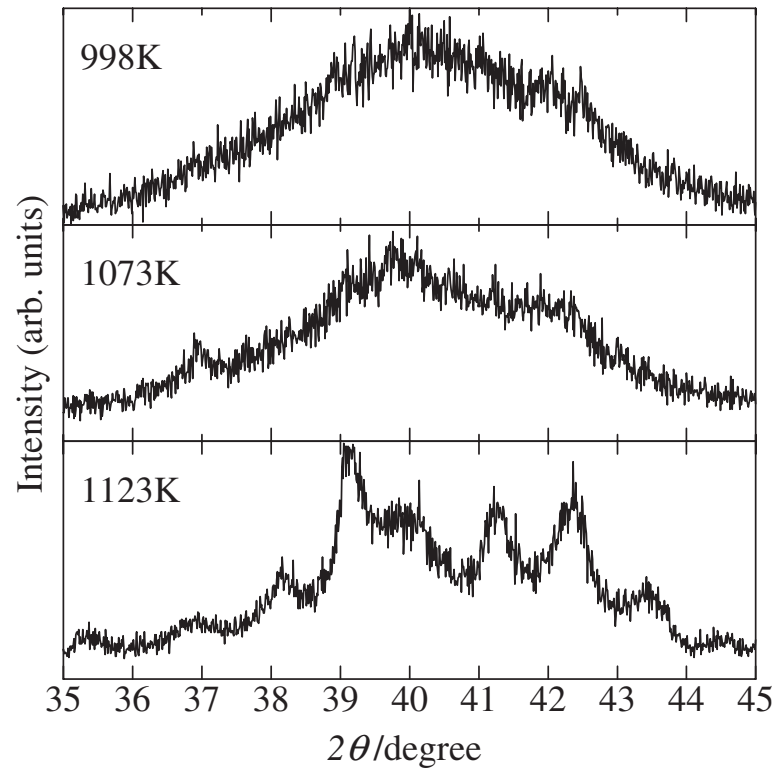

Fig. 6 High temperature X-ray diffraction spectra showing the change of the first hallow peak of as-quenched sample of $\mathrm{W}_{46} \mathrm{Ru}_{37} \mathrm{~B}_{17}$ alloy.

Table 2 Young's modulus $E$, Vickers hardness value $H_{\mathrm{V}}$ at room temperature and their ratio for $\mathrm{W}$-based metallic glasses.

\begin{tabular}{lccc}
\hline \multicolumn{1}{c}{ Alloy } & $E\left(10^{10} \mathrm{~Pa}\right)$ & $H_{\mathrm{V}}\left(10^{9} \mathrm{~Pa}\right)$ & $H_{\mathrm{V}} / E(\%)$ \\
\hline $\mathrm{W}_{46} \mathrm{Ru}_{37} \mathrm{~B}_{17}$ & $31.2 \pm 2$ & $16.8 \pm 1$ & $5.4 \pm 0.6$ \\
$\mathrm{~W}_{46} \mathrm{Ru}_{37} \mathrm{~B}_{15} \mathrm{Si}_{2}$ & $24.4 \pm 2$ & $14.4 \pm 1$ & $5.9 \pm 0.8$ \\
$\mathrm{~W}_{46} \mathrm{Ru}_{37} \mathrm{~B}_{12} \mathrm{Si}_{5}$ & $22.9 \pm 2$ & $13.2 \pm 1$ & $5.8 \pm 0.8$ \\
$\mathrm{~W}_{45} \mathrm{Ru}_{36} \mathrm{~B}_{17} \mathrm{Hf}_{2}$ & $26.2 \pm 2$ & $16.5 \pm 1$ & $6.2 \pm 0.8$ \\
$\mathrm{~W}_{45} \mathrm{Re}_{23} \mathrm{Ru}_{15} \mathrm{~B}_{17}$ & - & $17.3 \pm 1$ & - \\
\hline
\end{tabular}

crystallization temperature determined by the DSC measurement.

\subsection{Mechanical properties}

Measured Young's moduli for four samples are tabulated in Table 2. Since Young's moduli of pure tungsten, ruthenium and boron are $410 \mathrm{GPa}, 470 \mathrm{GPa}$ and $450 \mathrm{GPa}$, respectively, Young's moduli of the present W-based metallic glasses are about $30 \%$ lower than the weighted mean of Young's moduli of constituent elements, but they are the largest values among the reported Young's moduli of metallic glasses. It is found that substitution of Si considerably reduces the Young's modulus.

The sizes of indentation marks of micro-Vickers indentation at the load of $10 \mathrm{gf}$ or $20 \mathrm{gf}$ were about $3 \mu \mathrm{m}$ and $4.5 \mu \mathrm{m}$, respectively, which are an order smaller than the thickness of the sample, but those at the load of $100 \mathrm{gf}$ were as large as one-third of the sample thickness indicating a possible effect of the substrate. Nevertheless, the measured Vickers hardness values showed no appreciable thickness dependence, and hence the Vickers hardness value for each specimen was obtained by simply averaging the measured values. The Vickers hardness values thus-obtained at room temperature for five metallic glasses are given in Table 1 together with the ratio of Vickers hardness to Young's modulus, $H_{\mathrm{V}} / E$.

Temperature dependence of the Vickers hardness values 


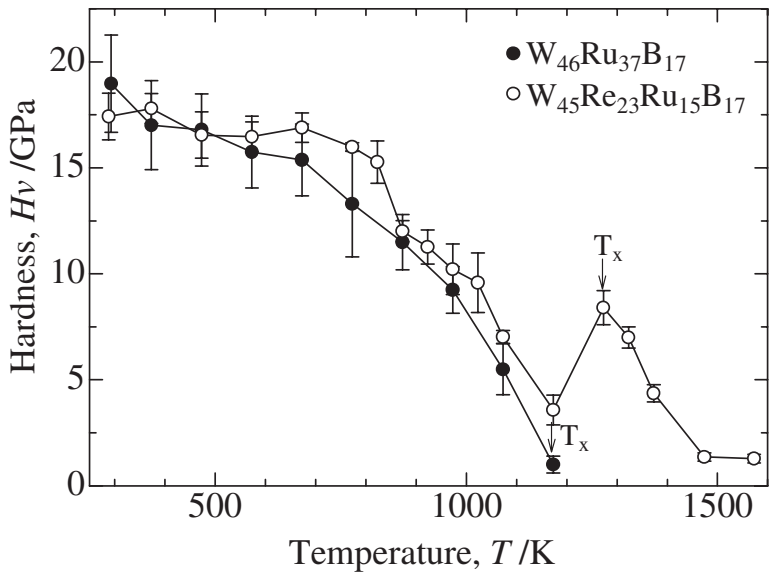

Fig. 7 Temperature dependence of Vickers hardness values for $\mathrm{W}_{46} \mathrm{Ru}_{37} \mathrm{~B}_{17}$ and $\mathrm{W}_{45} \mathrm{Re}_{23} \mathrm{Ru}_{15} \mathrm{~B}_{17}$ metallic glasses.

for $\mathrm{W}_{46} \mathrm{Ru}_{37} \mathrm{~B}_{17}$ and $\mathrm{W}_{45} \mathrm{Re}_{23} \mathrm{Ru}_{15} \mathrm{~B}_{17}$ metallic glasses is shown in Fig. 7. Due to the thin thickness of the samples, the data at high temperatures where the size of the indentation marks becomes as large as the thickness are not reliable and the true values may be larger than those measured. In both metallic glasses, the hardness keeps high values over $15 \mathrm{GPa}$ up to $700 \mathrm{~K}$ and over $10 \mathrm{GPa}$ up to $900 \mathrm{~K}$, but then decreases rapidly at high temperatures towards a very small minimum at around the glass transition temperature.

\section{Discussion}

\subsection{Glass forming ability}

At first, the fact that in most of the selected alloys a high quality amorphous alloy is produced indicates that alloy design for producing multi-component metallic glass based on binary eutectic compositions between base metal and alloying elements works well.

It is known that if $\Delta T_{\mathrm{x}}\left(=T_{\mathrm{x}}-T_{\mathrm{g}}\right)$ value is larger than $50 \mathrm{~K}$, it is possible to fabricate a bulk metallic glass. ${ }^{1)}$ Unfortunately, in the present DSC measurements, $T_{\mathrm{g}}$ values were only ill defined and it is impossible to evaluate correctly the glass forming ability for the present alloys. In any case, it seems necessary to tune the composition to have the highest glass forming ability for the present alloy systems.

\subsection{Crystallization temperature}

As was expected, the obtained crystallization temperatures of the W-based metallic glasses are quite high; they are between $1049 \mathrm{~K}$ and $1298 \mathrm{~K}$, which are much higher than those of conventional metallic glasses such as Zr-based metallic glasses having $T_{\mathrm{x}} \approx 750 \mathrm{~K}$. So far, several reports have been made of the production of refractory metal-based amorphous alloys by melt-quenching and their crystallization temperature. Refractory metal-based metallic glasses having the crystallization temperature higher than $1000 \mathrm{~K}$ are listed in Table 3. The highest crystallization temperatures have been reported for $(\mathrm{Ta}, \mathrm{W})_{80} \mathrm{Si}_{10} \mathrm{~B}_{10}\left(T_{\mathrm{x}}=1310 \sim 1456 \mathrm{~K}\right)$, and the present ones $\left(T_{\mathrm{x}}=1049 \sim 1298 \mathrm{~K}\right)$ for $\mathrm{W}$-based alloys are the next highest. As reported by Yoshitake et al., ${ }^{7}$ the higher is the melting point of an alloy, the higher is the crystallization temperature. As mentioned previously, to get higher
Table 3 Refractory metal-based metallic glasses having crystallization temperature higher than $1000 \mathrm{~K}$. TM: transition metal.

\begin{tabular}{|c|c|c|}
\hline Alloy & $T_{\mathrm{x}}(\mathrm{K})$ & Ref. No. \\
\hline$(\mathrm{Ta}, \mathrm{W})_{80} \mathrm{Si}_{10} \mathrm{~B}_{10}$ & $1310 \sim 1456$ & 7) \\
\hline$(\mathrm{Hf}, \mathrm{Ta})_{80} \mathrm{Si}_{10} \mathrm{~B}_{10}$ & $940 \sim 1220$ & 7) \\
\hline$(\mathrm{Ta}, \mathrm{Nb}, \mathrm{V})_{80} \mathrm{Si}_{10} \mathrm{~B}_{10}$ & $930 \sim 1210$ & 7) \\
\hline$(\mathrm{Nb}, \mathrm{Mo})_{80} \mathrm{Si}_{10} \mathrm{~B}_{10}$ & $1020 \sim 1120$ & 7) \\
\hline$(\mathrm{Cr}, \mathrm{TM})_{82} \mathrm{C}_{18}$ & $800 \sim 1035$ & 8) \\
\hline$(\mathrm{Nb}, \mathrm{Ta})_{55}(\mathrm{Rh}, \mathrm{Ir})_{45}$ & $951 \sim 1338$ & 9) \\
\hline $\mathrm{Nb}_{70} \mathrm{~W}_{10} \mathrm{Si}_{20}$ & 1027 & 10) \\
\hline $\mathrm{Nb}_{60} \mathrm{Mo}_{10} \mathrm{Si}_{20}$ & 1008 & 10) \\
\hline $\mathrm{W}_{70} \mathrm{Si}_{20} \mathrm{~B}_{10}$ & 1033 & 11) \\
\hline $\mathrm{Mo}_{48}, \mathrm{TM}_{32} \mathrm{P}_{12} \mathrm{~B}_{8}$ & $1078 \sim 1151$ & 12) \\
\hline$(\mathrm{Mo}, \mathrm{Cr}, \mathrm{Fe})_{80}(\mathrm{P}, \mathrm{B}, \mathrm{C}, \mathrm{Si})_{20}$ & $1104 \sim 1186$ & 12) \\
\hline$\left(\mathrm{Mo}_{0.6} \mathrm{Ru}_{0.4}\right)_{78-86} \mathrm{~B}_{22-14}$ & $1020 \sim 1090$ & 13) \\
\hline
\end{tabular}

glass forming ability the melting point should be lower, and hence the high crystallization temperature and the high glass forming ability are in a trade-off relation and difficult to be reconciled.

\subsection{Mechanical properties}

No Young's modulus data are available for refractory metal-based metallic glasses; the value of $312 \mathrm{GPa}$ obtained for $\mathrm{W}_{46} \mathrm{Ru}_{37} \mathrm{~B}_{17}$ metallic glass is probably the highest Young's modulus ever reported for metallic glasses. As far as the Young's modulus is concerned, Young's modulus of Ir is considerably higher than that of $\mathrm{W}$, and hence higher modulus metallic glass is expected to be obtained for Ir-based alloys.

Vickers hardness values higher than $10 \mathrm{GPa}$ reported for refractory metal-based metallic glasses are listed in Table 4. The highest hardness value was reported for a Mo-based metallic glass ${ }^{12)}$ and the hardness values of the present results on W-based alloys, $13 \sim 17 \mathrm{GPa}$, are almost comparable to those of Mo-based metallic glasses and to those of brittle Wbased metallic glasses. ${ }^{14)}$ No high temperature hardness data are available for refractory metal-based metallic glass, and the present results of the hardness value higher than $10 \mathrm{GPa}$ at $900 \mathrm{~K}$ is the highest Vickers hardness ever reported at this temperature for metallic glasses and probably even for any ductile materials.

As mentioned in Introduction, there exists a correlation

Table 4 Refractory metal-based metallic glasses having Vickers hardness values higher than $10 \mathrm{GPa}$.

\begin{tabular}{lllr}
\hline \multicolumn{1}{c}{ Alloy } & $H_{\mathrm{V}}(\mathrm{GPa})$ & \multicolumn{1}{c}{ Note } & Ref. No. \\
\hline$\left(\mathrm{Mo}_{0.6} \mathrm{Ru}_{0.4}\right)-\mathrm{B}$ & $12.6 \sim 18.0$ & brittle & $14)$ \\
$\left(\mathrm{Mo}_{0.6} \mathrm{Ru}_{0.4}\right)-\mathrm{Si}$ & $9.6 \sim 12.6$ & brittle & $14)$ \\
$\left(\mathrm{W}_{0.5} \mathrm{Ru}_{0.5}\right)-(\mathrm{B}, \mathrm{P}, \mathrm{Si})$ & $11.2 \sim 15.0$ & brittle & $14)$ \\
$(\mathrm{Cr}, \mathrm{TM})_{82} \mathrm{C}_{18}$ & $8.0 \sim 14.0$ & & $8)$ \\
$\mathrm{Mo}_{70} \mathrm{Si}_{20} \mathrm{~B}_{10}$ & 10.0 & & $11)$ \\
$\mathrm{W}_{70} \mathrm{Si}_{20} \mathrm{~B}_{10}$ & 13.0 & & $11)$ \\
$\mathrm{Mo}_{-} \mathrm{Fe}-\mathrm{B}$ & $17.5 \sim 19.5$ & & $12)$ \\
$\mathrm{Mo}_{-\mathrm{Co}-\mathrm{B}}$ & $16.5 \sim 17.0$ & & $12)$ \\
$\mathrm{Mo}_{\mathrm{Co}-\mathrm{Fe}-\mathrm{B}}$ & $17.5 \sim 17.8$ & & $12)$ \\
$\mathrm{Ta}_{55} \mathrm{Ir}_{45}$ & 17.3 & amorphous+crystals & $15)$ \\
\hline
\end{tabular}


between the modulus and the hardness: $H_{\mathrm{V}} / E=6.4 \pm 0.5 \%$ for metal-metal system and $H_{\mathrm{V}} / E=5.9 \pm 0.7 \%$ for metalmetalloid systems. ${ }^{4)}$ The present $H_{\mathrm{V}} / E$ values of $5.4 \sim 6.2 \%$ (Table 2) are in agreement with the previous results for metal-metalloid systems. To produce harder metallic glass, it seems necessary to use a base metal such as Ir having higher modulus than $\mathrm{W}$.

\section{Conclusion}

In an attempt to produce $\mathrm{W}$-based metallic glasses having high crystallization temperature and high hardness, ternary and quaternary W-based alloys were melt-spun. The compositions of the alloys have been determined based on eutectic compositions of W-based binary alloys. Results are summarized as follows.

(1) Most of the as-quenched samples are of single amorphous phase and are ductile.

(2) The onset temperatures of crystallization are between $1049 \mathrm{~K}$ and $1298 \mathrm{~K}$.

(3) Measured Young's moduli are between $229 \mathrm{GPa}$ and $313 \mathrm{GPa}$.

(4) Vickers hardness values at room temperature ranges from 13 to $17 \mathrm{GPa}$. The ratio of the Vickers hardness value to Young's modulus is near 0.06 in agreement with other metallic glasses.

(5) High temperature Vickers hardness values of $\mathrm{W}_{46} \mathrm{Ru}_{37} \mathrm{~B}_{17}$ and $\mathrm{W}_{45} \mathrm{Re}_{23} \mathrm{Ru}_{15} \mathrm{~B}_{17}$ metallic glasses are higher than $15 \mathrm{GPa}$ up to $700 \mathrm{~K}$ and higher than $10 \mathrm{GPa}$ up to $900 \mathrm{~K}$.

\section{Acknowledgments}

The authors are indebted to Prof. K. Edagawa of ISS of
The University of Tokyo for high temperature X-ray diffraction experiment and to Prof. I. Yonenaga of IMR of Tohoku University for high temperature Vickers hardness testing. One of the authors (M. O.) is grateful to Prof. S. Yoda of JAXA for his encouragement.

\section{REFERENCES}

1) A. Inoue: Bulk Amorphous Alloys-Properties and Fundamental Characteristics, (Trans Tech Publ, Switzerland, 1998).

2) A. Inoue: Bulk Amorphous Alloys-Practical Characteristics and Applications, (Trans Tech Publ, Switzerland, 1999).

3) S. H. Whang, D. E. Polk and B. C. Giessen: Proc. 4th Int Conf. on Rapidly Quenched Metals, ed. by T. Masumoto, K. Suzuki, (The Japan Inst. Metals, 1982) pp. 1365-1368.

4) S. Takeuchi and K. Maeda: Metallic and Semiconducting Glasses, ed. by A. K. Bhatnager, (Trans Tech Publ, Switzerland, 1987) pp. 749-759.

5) M. Ohtsuki, R. Tamura, S. Takeuchi, S. Yoda and T. Ohmura: Appl Phys. Lett. 84 (2004) 4911-4913.

6) D. Turnbull: Contemp. Phys. 10 (1969) 473-488.

7) T. Yoshitake, Y. Kubo and H. Igarashi: Mater. Sci. Eng. 97 (1988) 269271.

8) A. Inoue, S. Sakai, H. Kimura and T. Masumoto: Trans. JIM 20 (1979) 255-262.

9) C. C. Koch, D. M. Kroeger, J. O. Scarbrough and B. C. Giessen: Phys. Rev. B 22 (1980) 5213-5224.

10) T. Masumoto, A. Inoue, S. Sakai, H. Kimura and A. Hoshi: Trans. JIM 21 (1980) 115-122.

11) A. Inoue, S. Sakai, H. Kimura, K. Masumoto and A. Hoshi: Scr. Metall. 14 (1980) 235-239.

12) M. K. Mahan and B. L. Jha: J. Mater. Sci. Lett. 15 (1980) 1596-1598.

13) M. Mehra, R. Schultz and W. L. Johnson: J. Non-Cryst. Solids $61 \& 62$ (1984) 859-864.

14) W. L. Johnson and A. R. Williams: Phys. Rev. B 20 (1979) 1640-1655.

15) R. J. Wallace, E. N. Kaufmann and W. L. Bell: J. Mater. Res. 1 (1986) 758-764. 